\title{
Analysis of rice microbial communities under different storage conditions using
}

\section{culture-dependent and -independent techniques}

\author{
Xiaoying $\mathrm{He}^{1,2}$, Hairong Liu ${ }^{3}$, Chong $\mathrm{Lv}^{3}$, Feng Wang ${ }^{1,2}$, Chaoqun Zhao ${ }^{1,2}$, Rui Tao ${ }^{1,2}$, Jianpeng $\mathrm{Li}^{4}$, Zhu Liu ${ }^{1,2 *}$, \\ Lihui $\mathrm{Du}^{5 *}$ \\ ${ }^{1}$ Zhejiang Institute for Food and Drug Control, Hangzhou, China PR; ${ }^{2}$ Key Laboratory of Quality and Safety of Functional \\ Food for State Market Regulation, Hangzhou, China PR; ${ }^{3}$ Zhejiang Branch of China Grain Reserves Group Ltd. Company, \\ Hangzhou, China PR; ${ }^{4}$ Shandong Sinograin Quality Control Center of Grain and Oil Co., Ltd, Jinan, China PR; ${ }^{5}$ College of \\ Food Science and Engineering, Nanjing University of Finance and Economics, Nanjing, China PR
}

"Corresponding Authors: Lihui Du, College of Food Science and Engineering, Nanjing University of Finance and Economics, Nanjing 210023, Jiangsu, China. Email: ddabc_2000@163.com; Zhu Liu, Zhejiang Institute for Food and Drug Control, Hangzhou 310052, Zhejiang, China. Email: zliu82@126.com

Received: 13 October 2021; Accepted: 22 December 2021; Published: 20 January 2022 (C) 2022 Codon Publications

\section{OPEN ACCESS@(C) RESEARCH ARTICLE}

\begin{abstract}
Rice is a staple food for over half of the world's population, and fungal spoilage in stored rice may occur when the moisture content and temperature are conducive. Aspergillus sp. and Penicillium sp. are the most harmful toxigenic species that produce harmful mycotoxins. Molds pose a potential threat to public health and cause a huge economic loss. Therefore, it is of great importance to find out how molds multiply in rice. This study focused on the isolation and identification of fungi presented in rice and their evolution in rice with different moisture contents stored for varying periods of time and under different temperatures. Mold community was detected every month using the culture-dependent and -independent method of polymerase chain reaction-denaturing gradient gel electrophoresis (PCR-DGGE). Significant differences were detected by the traditional culture method under different storage conditions. For potato dextrose agar (PDA) media, high temperature and moisture were suitable for the dominant strains including Penicillium aurantiogriseum and Penicillium oxalicum. In particular, P. oxalicum competitively inhibited the other fungi. For Rose Bengal medium, no difference was observed under different storage conditions, and only typical strains such as Aspergillus candidus and Alternaria were detected. PCR-DGGE identified some uncultured strains such as Trichoderma sp. and Cladosporium sp., the dominant strains and the flora diversity such as Aspergillus restrictus and Eurotium athecium. These results indicated that storage conditions greatly shape fungal growth. This study provides a foundation for the evolution of fungal flora in rice during storage in China and may help in developing biological control methods to prevent mold contamination in rice.
\end{abstract}

Keywords: mold community; PCR-DGGE; rice; traditional culture

\section{Introduction}

Rice is one of the most important food in the world, and due to its high nutrition attributes such as protein, carbohydrates, minerals, and vitamins, it has become the main staple food in most places of the world (Cortés-Rojas et al., 2021; Naseer et al., 2014). To supply rice throughout the year, harvested rice need to be safely stored for a long time, even for years. Different from other cereals, most type of rice before harvest is cultivated in flooded conditions, which helps breeding of molds. Microbial species invade rice and its accessories (Park et al., 2005; 
Sempere and Santamarina, 2010). As the most populous country in the world, China needs to increase rice yield by approximately $20 \%$ by 2030 (Dong et al., 2017; Paterson and Lima, 2010).

Fungi play an important role in rice spoilage, and molds produce mycotoxins that may contaminate cereal grains at any stage during harvest, storage, or processing (Ali, 2016; Park et al., 2005). Various edible commodities from diverse meteorological regions are contaminated by different types of molds that produce distinct mycotoxins (Bennett and Klich, 2003; Sultana et al., 2015), such as aflatoxin B1 (AFB1), fumonisin B1 (FB1), ochratoxin A (OTA), trichothecenes, and zearalenone (ZEN), which can cause important social and economic concerns. Mold growth is influenced by multiple variables, such as water activity, temperature, and time. In general, moisture and temperature are the most critical factors during storage (Mohapatra et al., 2017; Gock MA et al., 2003). There are few studies that have focused on understanding and minimizing rice contamination. Lahouar et al. found that water activity and temperature can seriously affect Aspergillus flavus growth, and this result was confirmed by Somjaipeng and Ta-uea (Lahouar et al, 2016). Therefore, investigating the mechanism of mold evolution in rice might be beneficial in increasing rice production.

Culture-dependent analyses are efficient in determining fungi diversity in ecological studies during harvest and storage. Alternaria sp., Cladopoium sp., Fusarium sp., and Pullularia sp. are common field fungi species that contaminate grains, the genus of Aspergillus sp., Penicillium sp., and Fusarium sp. species was the most frequent species that is called storage fungi (Louis, 1969). Penicillium citrinum and Aspergillus candidus were the most prevalent species infecting the polished rice, while Fusarium proliferatum was found as the dominant (Park et al., 2005). All the above results are using cultural methods that are laborious and time-consuming. These include isolation, cultivation, and characterization of each species. Microorganisms are difficult to cultivate in the laboratory. In addition, the minor populations present are difficult to detect using cultural methods because they may be masked on the plates (Cocolin et al., 2013).

Culture-independent techniques have been widely applied for the efficient analysis of total mold diversity. Denaturing gradient gel electrophoresis (DGGE) is a culture-independent microbial technique that has been used to study microbial diversity, such as in kefir grains, animals, cheese and milk (Delgado et al., 2013; Demirci et al., 2021; El Sheikha, 2019; Jiang et al., 2010; Leite et al., 2012; Maturano et al., 2016). For example, the $28 \mathrm{~S}$ rDNA fingerprinting of fungal communities determined by PCRDGGE has been applied to detect the geographical origin of fruits (Sheikha et al., 2011). However, no attempt has been made to survey mycoflora in $\mathrm{r}$ ice i $\mathrm{n} \mathrm{C}$ hina. Therefore, the use of a combined approach may be advantageous to obtain additional detailed information.

This study explores fungal community and dominant mold strains under different conditions. To overcome the limitation of the culture-dependent method and get the rice microbial community from a culture-independent method, the microbial diversity of rice was investigated using polymerase chain reaction (PCR)-DGGE. The use of culture-independent method to investigate rice microbial community has theoretical and practical relevance in understanding community structure and rice microbe mechanism.

\section{Materials and Methods}

\section{Rice sample preparation}

Rice was harvested in Huaian Jiangsu province, China on October 10, 2020. Then the tests of the Huaidao No. 5 rice samples were sealed humidifier quenched at $14.5 \%$, $18.5 \%$ moisture content and were stored for 1 year at $25^{\circ} \mathrm{C}, 30^{\circ} \mathrm{C}$, and $35^{\circ} \mathrm{C}$, respectively. Mold variation was detected every month using culture-dependent techniques and PCR-DGGE.

\section{Isolation of fungal species}

Culturable fungal strains were isolated from freshly harvested rice sample according to China National Standard (GB 4789.15-2010) and placed in Rose Bengal and potato dextrose agar (PDA) media. For the preparation of a single colony, the isolated strains were further purified under the same conditions. For inoculum preparation, sterilized water was used to wash spores from plates after good sporulation (10 days). The spore suspension was stored at $4{ }^{\circ} \mathrm{C}$ for further studies.

\section{Identification of fungal species}

The fungal species were identified into species level on the basis of the morphological observation of colonies, hyphae, and spores in reference to $<$ Flora fungorum sinicorum $>$. All isolates of Aspergillus were assessed at 3, 5,7 , and 10 days of age to observe their morphological characteristics under different growth periods.

\section{Fungal DNA extraction}

The isolates of pure fungal strains for DNA extraction were subcultured on PDA and Rose Bengal media and 
incubated for 7 days at $37{ }^{\circ} \mathrm{C}$. Small hyphae with microloop were selected and placed in $50 \mu \mathrm{L}$ of lysis buffer at $80{ }^{\circ} \mathrm{C}$ for $15 \mathrm{~min}$. The purified DNA was stored at $4{ }^{\circ} \mathrm{C}$ until further analysis (Iheanacho et al., 2014).

\section{PCR reaction to amplify the ITS and $28 \mathrm{~S}$ gene of molds}

Taq DNA Polymerase was used for PCR following manufacturer's instructions (Dongsheng Biotech, Guangzhou, China). Amplification was carried out as follows: initial denaturation at $94^{\circ} \mathrm{C}$ for $10 \mathrm{~min}, 30$ cycles at $94^{\circ} \mathrm{C}$ for 30 $\mathrm{s}, 55^{\circ} \mathrm{C}$ for $30 \mathrm{~s}$ and $72^{\circ} \mathrm{C}$ for $30 \mathrm{~s}$, and a final extension at $72^{\circ} \mathrm{C}$ for $10 \mathrm{~min}$ (Dongsheng Biotech, Guangzhou, China). All PCR primers are listed in Table 1. Primers EF4 and Fungi5 were used to amplify the ITS regions of the molds. Primers NL1 and NL4 were used to amplify the $28 \mathrm{~S}$ regions of the molds. PCR was performed with the Taq DNA polymerase kit from Dongsheng Biotech (Guangzhou, China). The samples were amplified in a T1 Whatman Biometra (Applied Biosystems, Shanghai, USA) using the following program: $95^{\circ} \mathrm{C}$ for 5 min, and 30 cycles at $95{ }^{\circ} \mathrm{C}$ for $1 \mathrm{~min}, 50{ }^{\circ} \mathrm{C}$ for $1 \mathrm{~min}$, $72{ }^{\circ} \mathrm{C}$ for $30 \mathrm{~s}$, and $72{ }^{\circ} \mathrm{C}$ for a final $10 \mathrm{~min}$ extension. A horizontal electrophoresis apparatus (Bio-Rad, Shanghai, USA) on $2.0 \%(\mathrm{w} / \mathrm{v})$ agarose gels in $0.5 \mathrm{TAE}$ buffer was used to verify the PCR products. The gels were stained with ethidium bromide and visualized under UV light. PCR products were purified and sequenced by pEASY-T3 Cloning Vector (TransGen Biotech, Beijing, China) using an ABI3730 XL automatic DNA sequencer (Table 1).

The Basic Alignment Search Tool (BLAST) search was conducted to compare the obtained sequences with those published in National Center for Biotechnology Information (NCBI) database. The identification was verified as correct when the gene sequences showed $\geq 99 \%$ identity (Maturano et al., 2016).

\section{Electrophoretic conditions and identification of bands}

After the a culture-dependent experiment, a suspension was centrifuged at $15,000 \times \mathrm{g}$ at $4^{\circ} \mathrm{C}$ for $30 \mathrm{~min}$. In brief,
$50 \mu \mathrm{L}$ of supernatant was mixed with $50 \mu \mathrm{L}$ of lysis buffer at $80^{\circ} \mathrm{C}$ for $15 \mathrm{~min}$ in accordance with supplier's instructions. The $18 \mathrm{Sr}$ DNA region of molds was amplified using the universal primer pair NS1/GCFung, Taq DNA Polymerase (Dongsheng Biotech, Guangzhou, China) in the PCR reaction. Amplification was carried out with a PCR T1 Whatman Biometra (Applied Biosystems, Shanghai, USA) using a final volume of $25 \mu \mathrm{L}$ containing $12.5 \mu \mathrm{L}$ of Taq DNA polymerase, $1 \mu \mathrm{L}$ of each primer, $1 \mu \mathrm{L}$ of DNA template, and $9.5 \mu \mathrm{L}$ of dd $\mathrm{H}_{2} \mathrm{O}$ under the same conditions as above. DGGE electrophoresis was carried out by using a DCode apparatus (Bio-Rad, Shanghai, USA) at $60^{\circ} \mathrm{C}$ and employing $8 \%$ polyacrylamide gels with a denaturing range of $25 \%-35 \%$ for fungi. Electrophoresis was performed at $75 \mathrm{~V}$ for $7 \mathrm{~h}$ for fungal amplification.

Bands were stained with ethidium bromide $(0.5 \mathrm{mg} /$ $\mathrm{mL}$ ), visualized under UV light, then photographed. Sequences were used to identify the bands; bands were cut from the gels and bands with DNA eluted overnight in $50 \mu \mathrm{L}$ of sterile water at $4^{\circ} \mathrm{C}$. Same primer pairs without the GC-clamp were used to re-amplify and the DNA by the above condition. The identity of the sequences was determined by the BLAST algorithm in the GenBank database (Leite et al., 2012).

\section{Results}

In terms of fungal diversity in initial Huaidao No. 5 rice, 33 strains of fungi were isolated from the 2013 Huaidao No. 5 rice. These species were mainly Penicillium sp., Aspergillus sp., and Fusarium sp., including 16 strains of Penicillium sp. and 15 strains of Aspergillus sp. accounting for $48.5 \%$ and $45.5 \%$, respectively. Therefore, these two fungus genera are dominant in 2013 Huaidao No. 5 rice. Table 2 shows the detailed results. As shown in Figures 1 and 2, the different fungal genera were chosen as examples. Their morphological characteristics, hyphae, and spores were the preliminary determined in reference to <Flora fungorum sinicorum $>$. On the basis of ITS and 28S rDNA results, the precise conclusion was obtained as shown in Table 2.

Table 1. Primers used in this study.

\begin{tabular}{llr} 
Primer name & Sequence & Sequence length (bp) \\
\hline NS1 & 5'-GTAGTCATATGCTTGTCTC -3' & 340 \\
GCFung & 5'-CGCCCGCCGCGCCCCGCGCCCGECCGCCGCCCCCGCCCCATTCCCCGTTACCCGTTG -3' \\
EF4 & 5'-GGAAGGGRTGTATTTATTAG-3' & 580 \\
Fungi5 & $5^{\prime}$-GTAAAAGTCCTGGTTCCCC-3' & 560 \\
NL1 & 5'-GCATATCAATAAGCGGAGGAAAG -3' \\
NL4 & 5'-GGTCCGTGTTTCAAGACGG-3' & 5 \\
\hline
\end{tabular}


Table 2. BLAST results of initial rice sample based on the strains ITS and 28S rDNA sequences.

\begin{tabular}{|c|c|c|c|c|}
\hline Strain & Comparison result with ITS & Similarity $(\%)$ & Comparison result with $28 \mathrm{~S}$ & Similarity $(\%)$ \\
\hline $\mathrm{m} 23$ & Fusarium sp. & 99 & Fusarium fujikuroi & 99 \\
\hline $\operatorname{Pr}$ & Fusarium oxysporum & 99 & Fusarium sp. & 99 \\
\hline pe & Penicillium sp. & 99 & Penicillium sp. & 99 \\
\hline $\mathrm{Pj}$ & Penicillium sp. & 99 & Penicillium aurantiogriseum & 100 \\
\hline $\mathrm{Pd}$ & Penicillium sp & 100 & Penicillium aurantiogriseum & 99 \\
\hline $\mathrm{Pp}$ & Penicillium sp. & 100 & Penicillium aurantiogriseum & 99 \\
\hline m31 & Penicillium chrysogenum & 100 & Penicillium chrysogenum & 100 \\
\hline m32 & Penicillium chrysogenum & 100 & Penicillium chrysogenum & 99 \\
\hline $\mathrm{pD}$ & Penicillium decumbens & 99 & Penicillium oxalicum & 100 \\
\hline $\mathrm{Pb}$ & Penicillium sp. & 99 & Penicillium oxalicum & 100 \\
\hline Pv & Penicillium sp. & 99 & Penicillium oxalicum & 99 \\
\hline Mf & Penicillium sp. & 99 & Penicillium oxalicum & 99 \\
\hline $\mathrm{Mn}$ & Penicillium sp. & 99 & Penicillium sp. & 99 \\
\hline p11 & Penicillium sp. & 99 & Penicillium sp. & 99 \\
\hline p1 & Penicillium sp. & 100 & Penicillium aurantiogriseum & 99 \\
\hline p36 & Penicillium sp. & 100 & Penicillium sp. & 99 \\
\hline p12 & Penicillium sp. & 99 & Penicillium sp. & 99 \\
\hline pg & Penicillium sp. & 99 & Penicillium solitum & 99 \\
\hline $\mathrm{m} 27$ & Aspergillus sp. & 99 & Aspergillus protuberus & 100 \\
\hline mk & Aspergillus fumigates & 100 & Aspergillus fumigatus & 99 \\
\hline m5 & Aspergillus niger & 99 & Aspergillus protuberus & 99 \\
\hline ma & Aspergillus niger & 100 & Aspergillus niger & 99 \\
\hline p6 & Aspergillus sydowii & 100 & Aspergillus sydowii & 99 \\
\hline $\mathrm{mh}$ & Aspergillus niger & 99 & Aspergillus protuberus & 99 \\
\hline p2 & Aspergillus sp. & 99 & Aspergillus protuberus & 100 \\
\hline m003 & Aspergillus sydowii & 99 & Aspergillus sydowii & 100 \\
\hline p5 & Aspergillus niger & 99 & Aspergillus protuberus & 100 \\
\hline ps & Aspergillus niger & 99 & Aspergillus sydowii & 100 \\
\hline p10 & Aspergillus niger & 99 & Aspergillus versicolor & 99 \\
\hline $\mathrm{m} 30$ & Aspergillus niger & 99 & Aspergillus niger & 100 \\
\hline $\mathrm{m} 22$ & Aspergillus niger & 99 & Aspergillus niger & 100 \\
\hline m15 & Aspergillus niger & 99 & Aspergillus protuberus & 100 \\
\hline $\mathrm{m} 16$ & Aspergillus sp. & 99 & Aspergillus versicolor & 100 \\
\hline
\end{tabular}

\section{Culture-dependent analysis of fungal communities}

As shown in Figure 1, the community composition in Rose Bengal medium varied at different storage stages. A. candidus (band 7) and yeast (band 6) were the dominant species throughout the entire storage time. All strains were replaced by $A$. candidus at the last 3 months of storage. Alternaria sp. (band 3), Penicillium chrysogenum (band 2), Aspergillus niger (band 5), Aspergillus protuberus (band 4), and Aspergillus fumigatus (band 1) were also detected under different storage conditions. Alternaria sp. was one of the field fungi and disappeared after 2-4 months of storage. However, none of these mold strains were the dominant strain.
Figure 2 shows that in the PDA media, no dominant strains appeared in the initial 4 months of storage under all conditions, except at $18.5 \% / 30^{\circ} \mathrm{C}$ and $18.5 \% / 35^{\circ} \mathrm{C}$. At the 5 th month, P. aurantiogriseum (band 9) was detected in samples under $14.5 \% / 25^{\circ} \mathrm{C}$ and $14.5 \% / 30^{\circ} \mathrm{C}$ and persisted for 4 months. When the sample was cultured for 8 months, yeast (band 12) species were detected under $14.5 \% / 35^{\circ} \mathrm{C}$ and persisted for 1 month. Yeast was detected in PDA and Rose Bengal media and persisted from 3 months to 6 or 9 months under $30^{\circ} \mathrm{C}$. The emergence of yeast was earlier at $18.5 \%$ than at $14.5 \%$. P. oxalicum (band 10) was detected in the initial sample. After storing for 10 months, the dominant mold was replaced by $P$. oxalicum. Under $14.5 \% / 35^{\circ} \mathrm{C}$, Aspergillus glaucus 


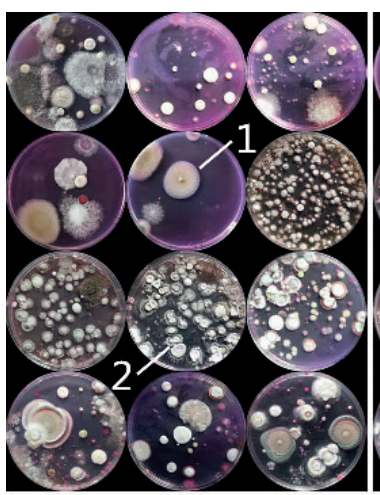

$\mathrm{W}: 14.5 \% \quad \mathrm{~T}: 25^{\circ} \mathrm{C}$

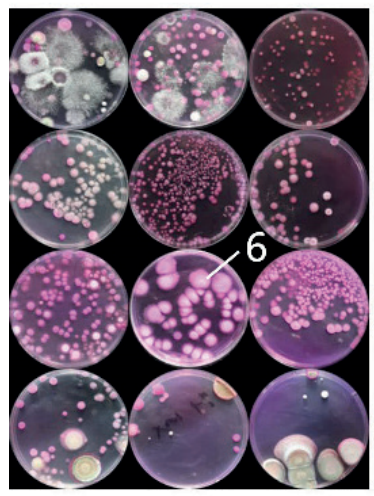

W: $180.5 \% \quad \mathrm{~T}: 25^{\circ} \mathrm{C}$

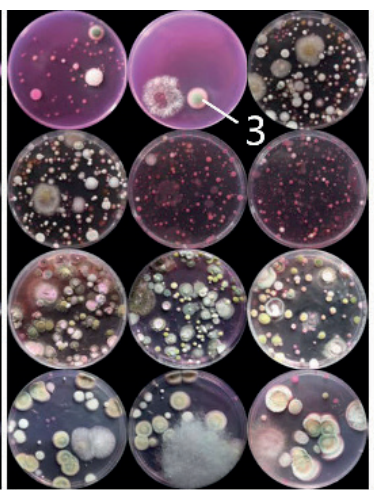

$\mathrm{W}: 14.5 \% \quad \mathrm{~T}: 30^{\circ} \mathrm{C}$

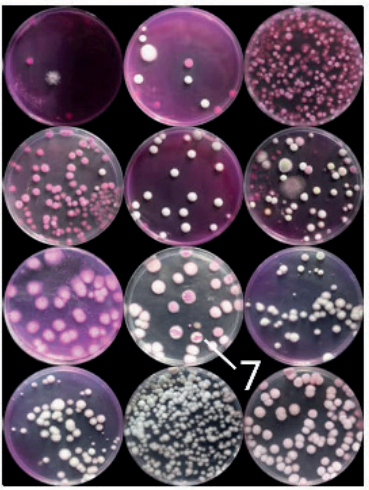

$\mathrm{W}: 18.5 \% \quad \mathrm{~T}: 30^{\circ} \mathrm{C}$
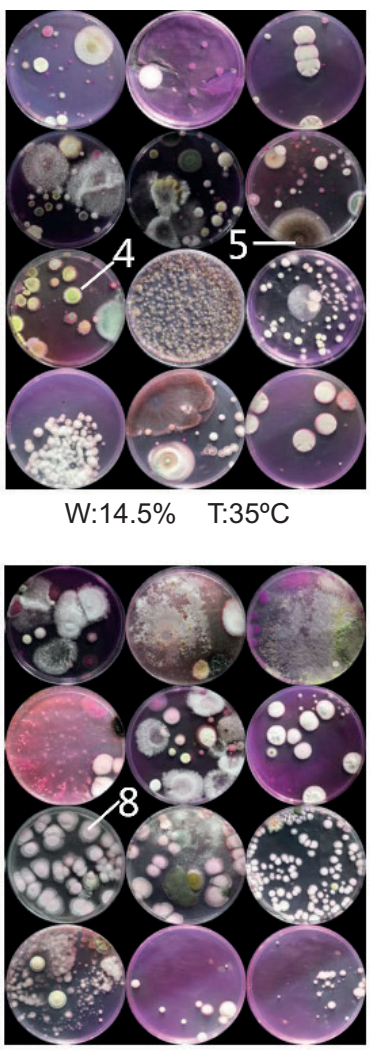

$\mathrm{W}: 18.5 \% \quad \mathrm{~T}: 35^{\circ} \mathrm{C}$

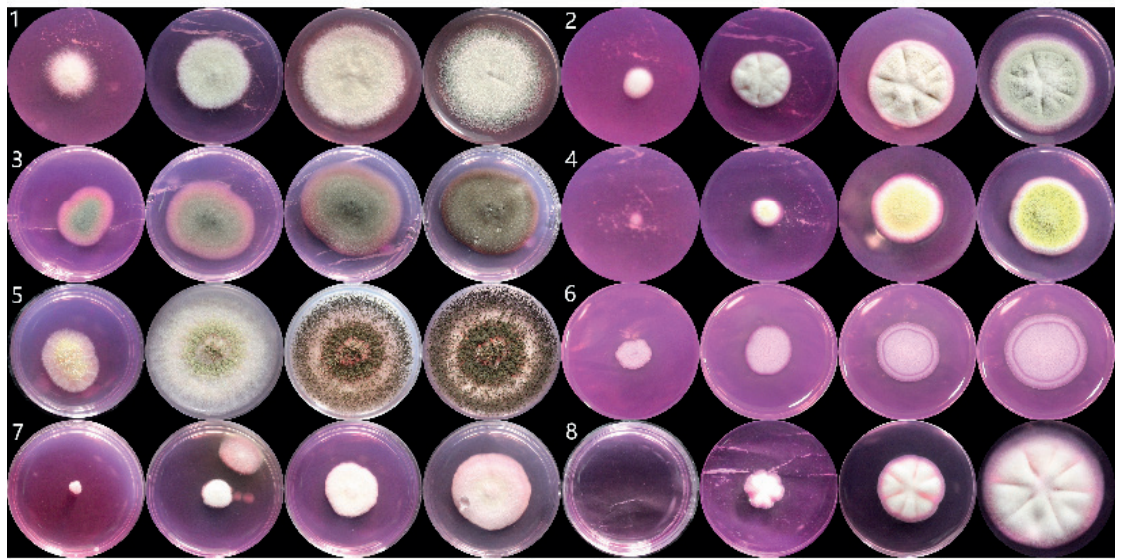

Figure 1. Pictures of the mold community on Rose Bengal medium from rice samples at storage time 1 to 12 months. Single colonies indicated by numbers 1 to 8 were collected and identified. Morphology of a single colony at $3,5,7$, and 10 days is shown in the last part of the picture.

(band 11) was also detected after 6 months of storage. All above fungi are shown in Figures 1 and 2 and Table 3.

\section{PCR-DGGE analysis of fungal communities}

A PCR-DGGE analysis of the fungi 18S rRNA gene was conducted on $12 \mathrm{RM}$ and the derived rice samples, with universal primers, were used to analyze the community structure of the dominant fungi using a cultureindependent technique.
Figure 3 and Table 4 show that band patterns differed for the rice samples under varying conditions and were almost identical for those under the same conditions. Twenty-eight high-intensity bands were cut and identified by re-amplification, sequencing, and sequence comparison (bands with a number on top in Figure 3). Table 4 summarizes the band identification results. Most bands were identified at the species level, and only seven bands were identified at the genus level. Some bands were labeled as uncultured fungi. Five bands belonged to Aspergillus sp., three to Penicillium sp., and two to 


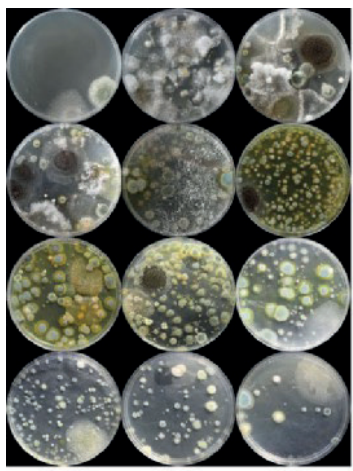

$\mathrm{W}: 14.5 \% \quad \mathrm{~T}: 25^{\circ} \mathrm{C}$

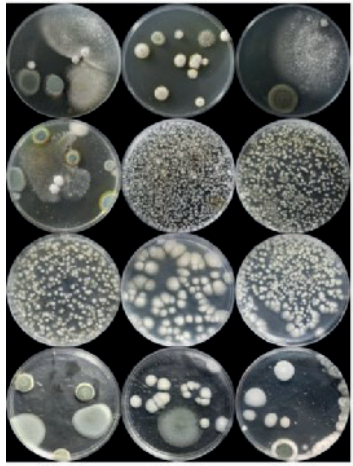

$\mathrm{W}: 180.5 \% \quad \mathrm{~T}: 25^{\circ} \mathrm{C}$

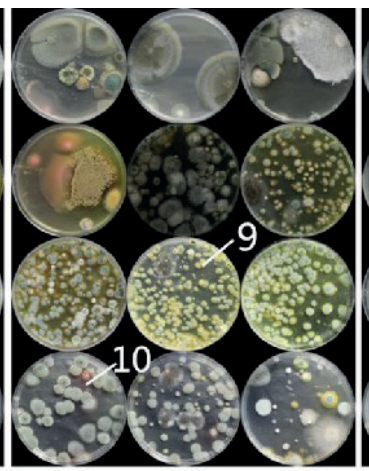

$\mathrm{W}: 14.5 \% \quad \mathrm{~T}: 30^{\circ} \mathrm{C}$

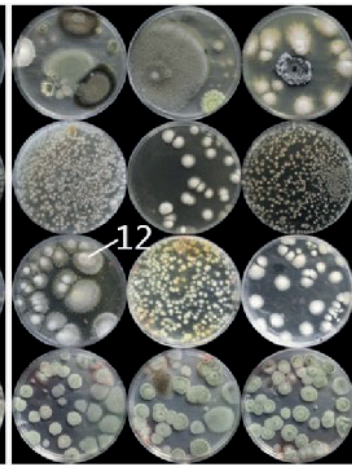

$\mathrm{W}: 18.5 \% \quad \mathrm{~T}: 30^{\circ} \mathrm{C}$

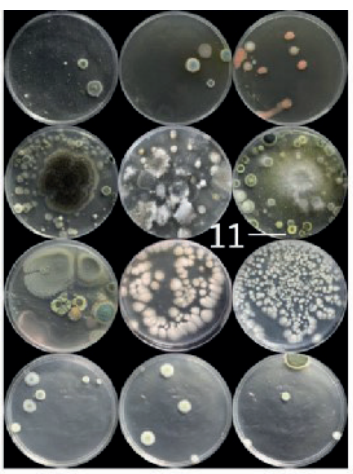

$\mathrm{W}: 14.5 \% \quad \mathrm{~T}: 35^{\circ} \mathrm{C}$

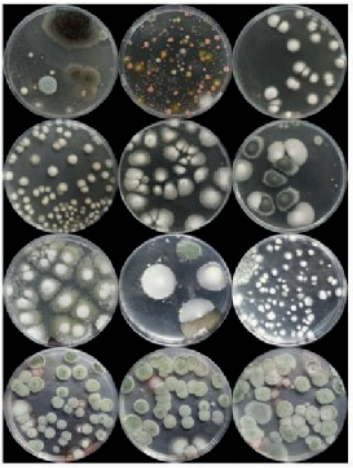

$W: 18.5 \% \quad \mathrm{~T}: 35^{\circ} \mathrm{C}$

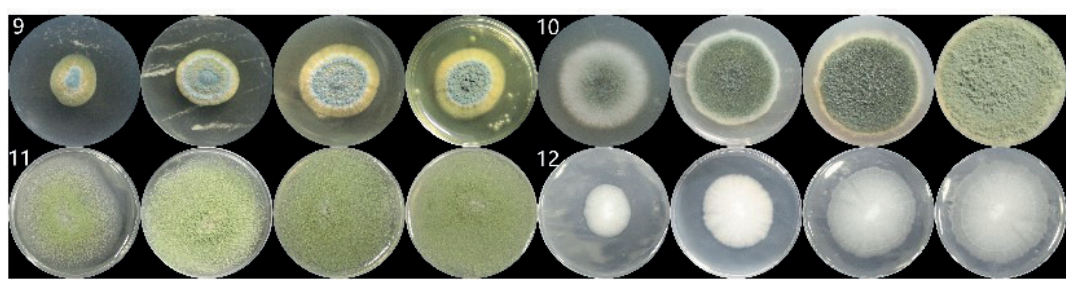

Figure 2. Pictures of the mold community on PDA medium from rice samples at storage time 1 to 12 months. Single colonies indicated by numbers 9 to 12 were collected and identified. Morphology of a single colony at 3, 5, 7, and 10 days is shown in the last part of the picture.

yeast. In addition to Aspergillus sp. and Penicillium sp., a culture-independent PCR-DGGE analysis detected other species such as Phoma, Cladosporium, Aureobasidium, Soliformovum, Hyphopichia burtonii, and Eurotium athecium. Most of these fungi cannot be detected by culture-dependent methods. Cladosporium is an intermediate mycoflora in most cereal grains and was detected in the rice sample stored for 3 months (FleuratLessard, 2017). The sample under $14.5 \% / 25^{\circ} \mathrm{C}$ produced 1-4 bands, where band 1 was $A$. versicolor, one of the initial fungi, and appears only under $14.5 \% / 25^{\circ} \mathrm{C}$. Therefore, this condition is suitable for the growth of $A$. versicolor. Different dominant molds were found under various temperatures. Under $18.5 \%$ moisture, the microbial communities were simple, especially when the temperature was high. Therefore, dominant strains can easily grow under high temperature and moisture. Under $18.5 \% / 30^{\circ} \mathrm{C}$ and $18.5 \% / 35^{\circ} \mathrm{C}$, the same dominant strains were identified.
Bands 23 and 26 were attributed to Aspergillus flavus, which produces toxic metabolites called aflatoxins that are potential threat human. Hence, inhibiting A. flavus growth or aflatoxin synthesis is crucial (Iqbal et al., 2006). Bands 24 and 27 correspond to Myrothecium roridum, a fungal plant pathogen. Myrotoxin B has been isolated from this organism. The sample under $14.5 \% / 30^{\circ} \mathrm{C}$ produced 5-9 high-intensity bands. Band 6 was $A$. candi$d u s$, which was also detected by the culture-dependent method, and band 9 was Penicillium commune. The sample under $14.5 \% / 35^{\circ} \mathrm{C}$ produced $10-13$ high-intensity bands when stored for 1 year. Band 10 was Penicillium purpurogenum, band 12 was Aspergillus ustus, and band 18 was Penicillium islandicum. Ji Yeon Oh reported that when the relative humidity increases, the abundance of $P$. islandicum also increases up to $40 \%-70 \%$ of total fungi in the stored rice sample (Oh et al., 2008). The sample under $18.5 \% / 25^{\circ} \mathrm{C}$ produced $14-20$ high-intensity bands. Band 
Table 3. BLAST results based on the strains ITS and 28S rDNA sequences of typical strains.

\begin{tabular}{llclr} 
Strain & Comparison result with ITS & Similarity (\%) & Comparison result with 28S & Similarity (\%) \\
\hline 1 & Aspergillus fumigatus & 99 & Aspergillus fumigatus & 99 \\
2 & Penicillium chrysogenum & 99 & Penicillium chrysogenum & 99 \\
3 & Alternaria & 99 & Alternaria & 99 \\
4 & Aspergillus protuberus & 99 & Aspergillus protuberus & 100 \\
5 & Aspergillus niger & 100 & Aspergillus niger & 99 \\
6 & Yeast & 100 & Yeast & 99 \\
7 & Aspergillus candidus & 100 & Aspergillus candidus & 100 \\
8 & Penicillium chrysogenum & 100 & Penicillium chrysogenum & 99 \\
9 & Penicillium aurantiogriseum & 99 & Penicillium aurantiogriseum & 100 \\
10 & Penicillium oxalicum & 99 & Penicillium oxalicum & 100 \\
11 & Aspergullus glaucus & 99 & Aspergullus glaucus & 99 \\
12 & Yeast & 99 & Yeast & 99
\end{tabular}

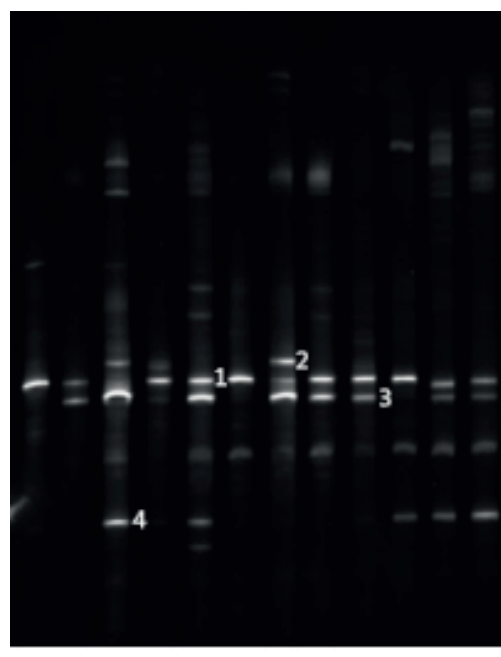

$\mathrm{W}: 14.5 \% \quad \mathrm{~T}: 25^{\circ} \mathrm{C}$

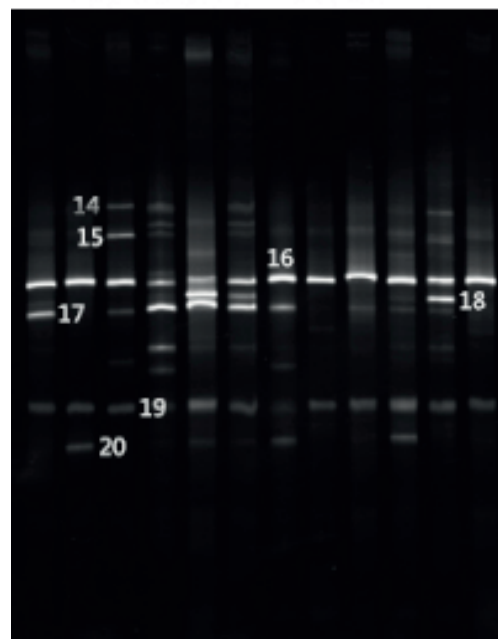

$\mathrm{W}: 180.5 \% \quad \mathrm{~T}: 25^{\circ} \mathrm{C}$

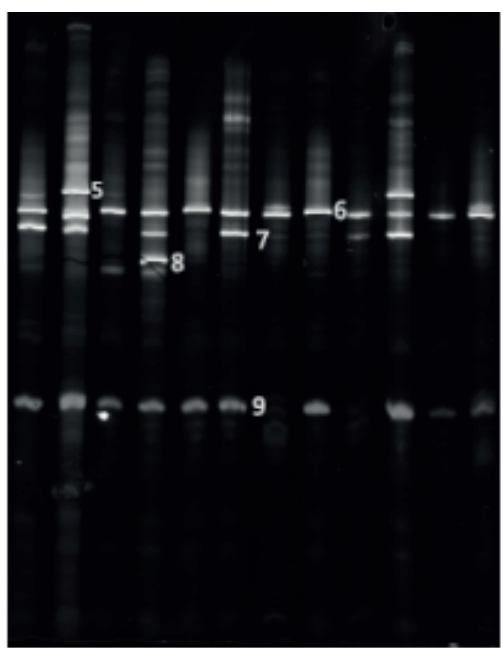

$\mathrm{W}: 14.5 \% \quad \mathrm{~T}: 30^{\circ} \mathrm{C}$

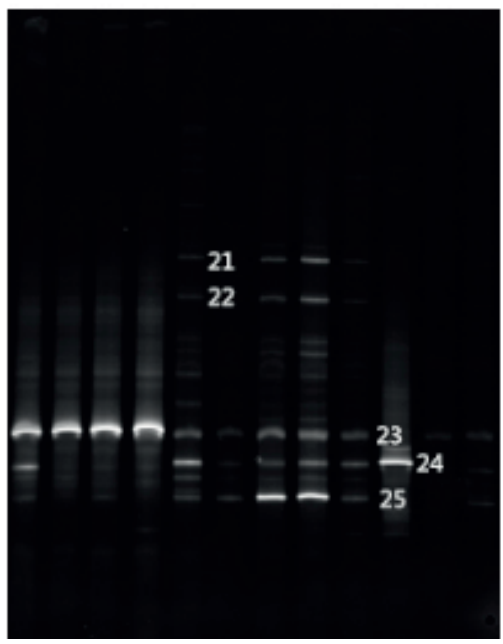

$\mathrm{W}: 18.5 \% \quad \mathrm{~T}: 30^{\circ} \mathrm{C}$

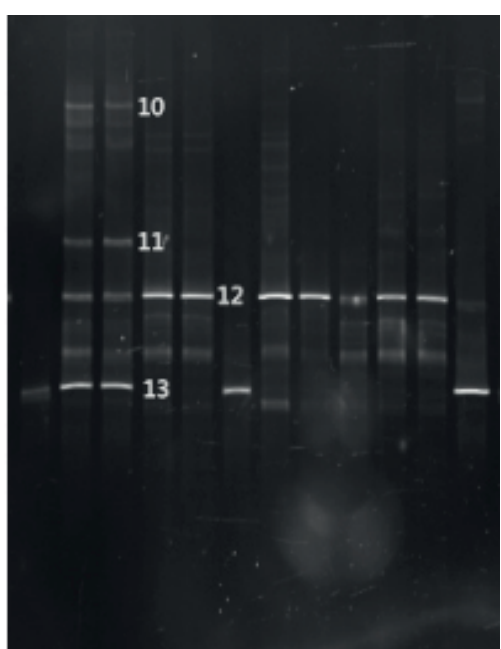

$\mathrm{W}: 14.5 \% \quad \mathrm{~T}: 35^{\circ} \mathrm{C}$

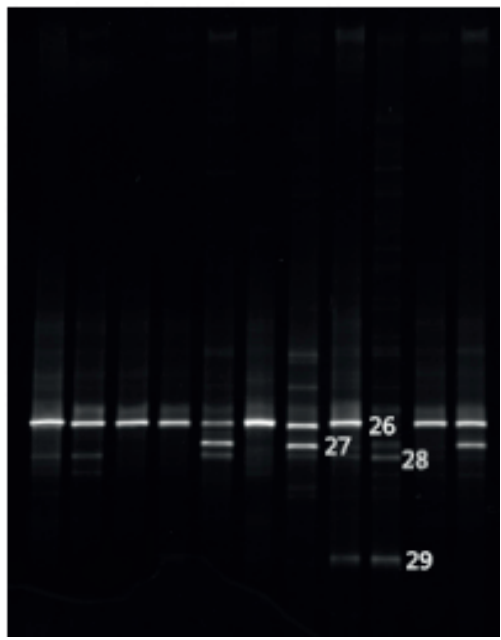

$\mathrm{W}: 18.5 \% \quad \mathrm{~T}: 35^{\circ} \mathrm{C}$

Figure 3. DGGE profiles of the mold community from DNA directly extracted from rice samples at storage time 1 to 12 months. Bands indicated by numbers 1 to 29 were excised and, after re-amplification, subjected to sequencing. The bands are discussed in the text, and the positions of the bands are indicated on the right. 
Table 4. Strains and DGGE bands identified in this study using partial 18S rRNA gene sequencing.

\begin{tabular}{|c|c|c|c|}
\hline Bands & Closest relative & Identity & $\begin{array}{l}\text { Accession } \\
\text { No. }\end{array}$ \\
\hline 1 & Aspergillus versicolor & $100 \%$ & AB002064.1 \\
\hline 2 & Cladosporium sp. & $100 \%$ & JQ824844.1 \\
\hline 3 & Talaromyces purpurogenus & $100 \%$ & KC009578.1 \\
\hline 4 & Hyphopichia burtonii & $99 \%$ & AB018177.1 \\
\hline 5 & Eurotium athecium & $100 \%$ & KJ126879.1 \\
\hline 6 & Aspergillus candidus & $99 \%$ & KJ126884.1 \\
\hline 7 & Apergillus restrictus & $99 \%$ & KR123678.1 \\
\hline 8 & Aureobasidium & $100 \%$ & KJ561257.1 \\
\hline 9 & Talaromyces purpurogenus & $100 \%$ & KC009578.1 \\
\hline 10 & Uncultured Archaeospora & $100 \%$ & KT923272.1 \\
\hline 11 & Soliformovum & $90 \%$ & FJ766479.1 \\
\hline 12 & Aspergillus ustus & $99 \%$ & KR063174.1 \\
\hline 13 & Aspergillus penicillioides & $99 \%$ & DQ985959.1 \\
\hline 14 & Uncultured Ascomycota & $99 \%$ & KF650047.1 \\
\hline 15 & Uncultured eukaryote & $100 \%$ & JX099065.1 \\
\hline 16 & Aspergillus ustus & $99 \%$ & KR063174.1 \\
\hline 17 & Penicillium commune & $99 \%$ & KF018446.1 \\
\hline 18 & Penicillium islandicum & $100 \%$ & AY373919.1 \\
\hline 19 & Penicillium purpurogenum & $100 \%$ & JX022616.1 \\
\hline 20 & Fungal sp. & $100 \%$ & HQ132705.1 \\
\hline 21 & Rhizopus oryzae & $99 \%$ & AY213624.1 \\
\hline 22 & Uncultured plosporales & $98 \%$ & KF650048.1 \\
\hline 23 & Penicillium oxalicum & $99 \%$ & KR063176.1 \\
\hline 24 & Myrothecium roridum & $98 \%$ & KR063175.1 \\
\hline 25 & Uncultured fungus & $100 \%$ & KR906021.1 \\
\hline 26 & Penicillium oxalicum & $99 \%$ & KR063176.1 \\
\hline 27 & Myrothecium roridum & $98 \%$ & KR063175.1 \\
\hline 28 & Phoma & $99 \%$ & KM387394.1 \\
\hline 29 & Hyphopichia burtonii & $99 \%$ & AB018177.1 \\
\hline
\end{tabular}

28 was Phoma, one of the field strains. The sample under $18.5 \% / 35^{\circ} \mathrm{C}$ produced four bands, but only the bright ones were evident. Bands 23 and 26 were attributed to P. oxalicum.

\section{Discussion}

The microbial diversity and community structure of rice were analyzed using both culture-dependent and -independent techniques under different storage time and conditions. The results provide a complete view of the overall composition of rice communities.

P. oxalicum and $P$. aurantiogriseum were detected from the initial and stored samples and on PDA media regardless of the condition. The dominant strain was replaced by P. oxalicum in the last few storage months. PCR-DGGE results show that $P$. oxalicum was the dominant strain under the condition of $18.5 \% / 30^{\circ} \mathrm{C}$ and $18.5 \% / 35^{\circ} \mathrm{C}$, indicating that this species can grow at higher temperatures and humidity than other fungi. P. oxalicum is an effective biological control agent against other fungal species, such as Fusarium oxysporum (Cal et al., 2001, 2010) and Verticillium dahliae (Larena et al., 2010; Sabuquillo et al., 2005, 2006). An analysis on the antagonistic effect of $P$. oxalicum on A. alternata in rice under different temperature and water activity found that $P$. oxalicum is a good biological control agent of rice fungi pathogens (Sempere and Santamarina, 2010). This antagonistic agent was also tested for strawberry, pea, and tomato fungal strains, and other crop pathogens with good results (Cal et al., 2001, 2008; Windels and Kommedahl, 1982). In the present work, P. oxalicum produced red liquid; further work must explore the specific mechanisms of this red liquid. This finding may provide a new research direction for the control and prevention of rice mold contamination (Li et al., 2015). P. aurantiogriseum is commonly found in stored cereals and is a potential producer of mycotoxins and a broad spectrum of volatile metabolites (Brjesson $\mathrm{T}$ et al., 1990). This fungus produces a type of liquid that can inhibit other strains. Additional experiments are needed to study the specific mechanism. Aspergillus spp. are the most typical fungal species responsible for cereal spoilage. These species include $A$. fumigatus, $A$. protuberus, $A$. candidus, $A$. glaucus, $A$. versicolor, $A$. restrictus, $A$. ustus, and $A$. penicillioides. Aspergillus species are most dominant among food deteriorating molds. These fungi widely occur in food, particularly in starchy cereal grains such as wheat, maize, rice, and barley and may produce toxic secondary metabolites called aflatoxins. The current findings are in agreement with Mannaa and Kim (2017). A protuberus SP1 was isolated from Marine Sediments of the South Indian Coast and showed activity against human pathogens (Mathan et al., 2011). Oh identified three predominant Aspergillus species from five regions in Korean stored rice, namely, A. candidus, A. flavus, and A. fumigatus (Oh et al., 2010). In this work, A. candidus was detected under $18.5 \% / 30^{\circ} \mathrm{C}$. This mold is common in stored food grains (Chattopadhyay et al., 1987). Humidity is one of the crucial factors affecting the biodiversity and evolution of mold species during storage. The present results reveal that $P$. aurantiogriseum prefers a lower humidity than yeast species and is significantly positively correlated at $14.5 \% / 25^{\circ} \mathrm{C}$ and $14.5 \% / 30^{\circ} \mathrm{C}$. By contrast, yeast species require a high humidity (18.5\%). P. aurantiogriseum cannot survive when the moisture content is above $18.5 \%$ (Fleurat-Lessard, 2017). The optimal conditions for molds are extremely important: $P$. oxalicum performed and acclimatized best at $14.5 \% / 30^{\circ} \mathrm{C}$, $18.5 \%\left(30^{\circ} \mathrm{C}-35^{\circ} \mathrm{C}\right)$, and $A$. candidus grew optimally at high temperature and humidity of $18.5 \%\left(30^{\circ} \mathrm{C}-35^{\circ} \mathrm{C}\right)$. During storage, the dominant strains benefited from 
the high storage temperature and humidity. The present results reveal that $P$. oxalicum is strongly dominant in the PDA media. Water activity is the main environmental factor governing the predominance of fungal groups on grains, and this finding is in harmony with the current study.

Differences in results may be attributed to several reasons. Some uncultured species are unable to grow on artificial media. The number of fungi identified by DGGE is smaller than that by traditional culture (Duong et al., 2006). In this work, the dominant strains P. oxalicum, $P$. aurantiogriseum, and $A$. candidus were detected through cultivation but not by PCR-DGGE. This bias may be caused by differences in the efficiency of DNA extraction or the preferential amplification of the primers for some sequences (Wang et al., 2015). Meanwhile, not all species are efficiently amplified with PCR-DGGE primers. P. oxalicum exhibited poor PCR efficiency with the $18 \mathrm{~S}$ primer set. Therefore, P. oxalicum was not detected in DGGE gels but was observed in the culturable community. A similar situation was observed for two other species, $P$. aurantiogriseum and $A$. candidus. The dominant strain was detected by PCR-DGGE probably because it was a part of the major population in the grains. Rapidly growing fungi can absorb more nutrition than others and thus inhibit their growth, leading to species diversity loss. In general, PCR-DGGE using a part of the 18S rRNA gene is often seen as an alternative or complement of culture-independent approach in investigating the biodiversity of microbial ecosystems. Owing to the technical deficiencies of PCR-DGGE, however, some elements of the microbial community might not be detected. Other new technologies, such as T-RLFP, MLST, and high-throughput sequencing, must be adopted for further studies (Paola et al., 2016).

In conclusion, the combination of these two methods provide a complete overview of the rice community. P. oxalicum was identified as the dominant strain and detected even in the initial sample. During storage, P. oxalicum competitively inhibits the other fungi. Field fungi (especially Fusarium) and stored fungi (especially Penicillium and Aspergillus) have different suitable storage conditions. Culture-independent and -dependent techniques must be combined to obtain total counts and provide a complete overview of the ecosystem biodiversity. This study contributes to the understanding of rice evolution at different storage conditions and provides scientific data and theoretical support for further research on stored grain fungi.

\section{Conflict of Interest}

The authors declare that they have no conflicts of interest.

\section{Funding}

This work was financially supported by The National Key Research and Development Program of China (2018YFC1603300), Market Supervision Authority Research Project of Zhejiang Province(20210126), Public Projects of Zhejiang Province (LGC19C200001).

\section{References}

Ali S, 2016. Aflatoxigenic fungi in food grains: Detection, its impact on handlers and management strategies. In: Kumar P, Gupta V, Tiwari A, Kamle M. (eds). Current trends in plant disease diagnostics and management practices. Cham: Springer; p. 441-57. https://doi.org/10.1007/978-3-319-27312-9_20

Sheikha, AFE, Bouvet, JM, \& Montet, D, 2011. Biological bar code for determining the geographical origin of fruits using $28 \mathrm{~s}$ rDNA fingerprinting of fungal communities by PCR-DGGE: An application to shea tree fruits. Qual Assur Saf Crop., 3(1):40-7. https://doi.org/10.1111/j.1757-837X.2010.00090.x

Bennett JW, Klich M, 2003. Mycotoxins. Clin Microbiol Rev., 16:497-516. https://doi.org/10.1128/CMR.16.3.497-516.2003

Brjesson T, Stllman U, Schnürer J, 1990. Volatile metabolites and other indicators of Penicillium aurantiogriseum growth on different substrates. Appl Environ Microbiol., 56(12):3705-10. https://doi.org/10.1128/aem.56.12.3705-3710.1990

Cal AD, Melgarejo P., 2001. Repeated applications of Penicillium oxalicum prolongs biocontrol of fusarium wilt of tomato plants. Eur J Plant Pathol., 107(8):805-11. https://doi. org/10.1023/A:1012432404886

Cal AD, Pascual S, Larena I, Melgarejo P, 2010. Biological control of Fusarium oxysporum f. sp. lycopersici. Plant Pathol ., 44(5):90917. https://doi.org/10.1111/j.1365-3059.1995.tb02750.x

Cal AD, Redondo C, Sztejnberg A, Melgarejo P, 2008. Biocontrol of powdery mildew by Penicillium oxalicum in open-field nurseries of strawberries. Biol Control., 47(1):103-7. https://doi. org/10.1016/j.biocontrol.2008.07.010

Chattopadhyay SK, Nandi B, Ghosh P, Thakur S, 1987. A new mycotoxin from Aspergillus candidus link isolated from rough rice. Mycopathologia., 98(1):21-6. https://doi.org/10.1007/ BF00431013

Cocolin L, Alessandria V, Dolci P, Gorra R, Rantsiou K, 2013. Culture independent methods to assess the diversity and dynamics of microbiota during food fermentation. Int J Food Microbiol., 167(1):29-43. https://doi.org/10.1016/j.ijfoodmicro.2013.05.008

Cortés-Rojas D, Beltrán-Acosta C, Zapata-Narvaez Y, Chaparro M, Cruz-Barrera M, 2021. Seed coating as a delivery system for the endophyte trichoderma koningiopsis th003 in rice (Oryza sativa). Appl Microbiol Biotechnol., 105(1889-1904). https:// doi.org/10.1007/s00253-021-11146-9

Delgado S, Rachid CT, Fernández E, Rychlik T, Alegría Á, Peixoto RS, et al., 2013. Diversity of thermophilic bacteria in raw, pasteurized and selectively-cultured milk, as assessed by culturing, PCR-DGGE and pyrosequencing. Food Microbiol., 36(1):103-11. https://doi.org/10.1016/j.fm.2013.04.015 
Demirci T, Akin N, Atik DS, Zkan ER, Akyol S, 2021. Lactic acid bacteria diversity and dynamics during ripening of traditional Turkish goatskin tulum cheese produced in Mut region assessed by culturing and PCR-DGGE. LWT - Food Sci Technol., 138(5):110701. https://doi.org/10.1016/j.lwt.2020.110701

Dong H, Chen Q, Wang W, Peng S, Huang J, Cui K, et al., 2017. The growth and yield of a wet-seeded rice-ratoon rice system in central China. Field Crops Res., 208:55-9. https://doi.org/10.1016/j. fcr.2017.04.003

Duong LM, Jeewon R, Lumyong S, Hyde KD, 2006. DGGE coupled with ribosomal DNA gene phylogenies reveal uncharacterized fungal phylotypes. Fungal Diversity., 23(6):121-138. http://hdl. handle.net/10722/223170

El Sheikha A, 2019. Molecular detection of mycotoxigenic fungi in foods: The case for using PCR-DGGE. Food Biotechnol., 33(1):54-108. https://doi.org/10.1080/08905436.2018.1547644

Fleurat-Lessard F, 2017. Integrated management of the risks of stored grain spoilage by seedborne fungi and contamination by storage mould mycotoxins - An update. J Stored Prod Res., 71:22-40. https://doi.org/10.1016/j.jspr.2016.10.002

Gock MA, Hocking AD, Pitt JI, Poulos PG, 2003. Influence of temperature, water activity and $\mathrm{pH}$ on growth of some xerophilic fungi. Int J Food Microbiol., 81(1):11-19. https://doi. org/10.1016/S0168-1605(02)00166-6

Iheanacho HE, Njobeh PB, Dutton FM, Steenkamp PA, Steenkamp L, Mthombeni JQ, et al., 2014. Morphological and molecular identification of filamentous Aspergillus flavus and Aspergillus parasiticus isolated from compound feeds in South Africa. Food Microbiol., 44:180-4. https://doi.org/10.1111/jfpp.14178

Iqbal A, Khalil IA, Shah H, 2006. Aflatoxin contents of stored and artificially inoculated cereals and nuts. Food Chem., 98(4):699703. https://doi.org/10.1016/j.foodchem.2005.06.034

Jiang Y, Gao F, Xu XL, Su Y, Ye KP, Zhou GH, 2010. Changes in the bacterial communities of vacuum-packaged pork during chilled storage analyzed by PCR-DGGE. Meat Sci., 86(4):889-95. https://doi.org/10.1016/j.meatsci.2010.05.021

Lahouar A, Marin S, Crespo-Sempere A, Saïd S, Sanchis V, 2016. Effects of temperature, water activity and incubation time on fungal growth and aflatoxin B1 production by toxinogenic Aspergillus flavus isolates on sorghum seeds. Rev. Argent. Microbiol., 48(1):78-85. https://doi.org/10.1016/j. ram.2015.10.001

Larena I, Sabuquillo P, Melgarejo P, Cal AD, 2010. Biocontrol of fusarium and verticillium wilt of tomato by Penicillium oxalicum under greenhouse and field conditions. J Phytopathol., 151(9):507-12. https://doi.org/10.104.6/j.1439-0434.2003.00762.x

Leite AM, Mayo B, Rachid CT, Peixoto RS, Silva JT, Paschoalin VMF, et al., 2012. Assessment of the microbial diversity of Brazilian kefir grains by PCR-DGGE and pyrosequencing analysis. Food Microbiol., 31(2):215-21. https://doi.org/10.1016/j. fm.2012.03.011

Louis Feinstein, 1969. Grain Storage-the Role of Fungi in Quality Loss, Bulletin of the Entomological Society of America, 15(3):259. https://doi.org/10.1093/besa/15.3.259

Li QQ, Dang L Z, Zhang YP, Jiang J X, Zhang CM, Xiang NJ, et al., 2015. Isocoumarins from the fermentation products of a plant entophytic fungus Penicillium oxalicum. Nat Prod Res., 17(9):876-81. https://doi.org/10.1080/10286020.2015.1039997

Mannaa M, Kim KD, 2017. Influence of temperature and water activity on deleterious fungi and mycotoxin production during grain storage. Mycobiology., 45(4):240-54. https://doi. org/10.5941/MYCO.2017.45.4.240

Mathan, S, Smith, AA, Kumaran, J, \& Prakash, S, 2011. Anticancer and antimicrobial activity of Aspergillus protuberus sp1 isolated from marine sediments of south Indian coast. Chinese J Nat Med., 4: 286-292. http://www.cqvip.com/ QK/86968X/201104/38511487.html

Maturano YP, Mestre MV, Combina M, Toro ME, Vazquez F, Esteve-Zarzoso B, 2016. Culture-dependent and independent techniques to monitor yeast species during cold soak carried out at different temperatures in winemaking. Int J Food Microbiol., 237:142-9. https://doi.org/10.1016/j. ijfoodmicro.2016.08.013

Mohapatra D, Kumar S, Kotwaliwale N, Singh KK, 2017. Critical factors responsible for fungi growth in stored food grains and non-chemical approaches for their control. Ind Crops Prod., 108:162-82. https://doi.org/10.1016/j.indcrop.2017.06.039

Naseer R, Sultana B, Khan MZ, Naseer D, Nigam P, 2014. Utilization of waste fruit-peels to inhibit aflatoxins synthesis by Aspergillus flavus: A biotreatment of rice for safer storage. Bioresource Technol., 172:423-8. https://doi.org/10.1016/j. biortech.2014.09.017

Oh JY, Kim EN, Ryoo MI, Kim KD, 2008. Morphological and molecular identification of Penicillium islandicum isolate KU101 from stored rice. Plant Pathol J., 24(4):469-73. https://doi. org/10.5423/PPJ.2008.24.4.469

Oh JY, Sang MK, Oh JE, Lee HJ, Ryoo MI, Kim KD, 2010. Microbial population, aflatoxin contamination, and predominant Aspergillus species in Korean stored rice. Plant Pathol J., 26(2):121-9. https://doi.org/10.5423/PPJ.2010.26.2.121

Paola M, Victoria M, Mariana C, Maria ET, 2016. Culturedependent and independent techniques to monitor yeast species during cold soak carried out at different temperatures in winemaking - ScienceDirect. Int J Food Microbiol., 237:142-9. https://doi.org/10.1016/j.ijfoodmicro.2016.08.013

Park JW, Choi SY, Hwang HJ, Kim YB, 2005. Fungal mycoflora and mycotoxins in Korean polished rice destined for humans. IntJ Food Microbiol., 103(3):305-14. https://doi.org/10.1016/j. ijfoodmicro.2005.02.001

Paterson RRM, Lima N, 2010. How will climate change affect mycotoxins in food? Food Res Int., 43(7):1902-14. https://doi. org/10.1016/j.foodres.2009.07.010

Sabuquillo P, Cal AD, Melgarejo P, 2005. Dispersal improvement of a powder formulation of Penicillium oxalicum, a biocontrol agent of tomato wilt. Plant Dis., 89(12):1317-23. https://doi. org/10.1094/PD-89-1317

Sabuquillo P, Cal,AD, Melgarejo P, 2006. Biocontrol of tomato wilt by Penicillium oxalicum formulations in different crop conditions. Biol Control., 37(3):256-65. https://doi.org/10.1016/j. biocontrol.2006.02.009

Sempere F, Santamarina MP, 2010. Study of the interactions between Penicillium oxalicum Currie \& Thom and Alternaria 
alternata (Fr.) Keissler. Brazilian J Microbiol., 41(3):700-6. https://doi.org/10.1590/S1517-83822010005000003

Somjaipeng S, Ta-uea P, 2016. Evaluation of the effect of water activity and temperature on lag phase and growth rate of aflatoxigenic aspergillus section flavi strains isolated from stored rice grain. Agric Agric Sci Proc., 11:38-45. https://doi.org/10.1016/j. aaspro.2016.12.007

Sultana B, Naseer R, Nigam P, 2015. Utilization of agro-wastes to inhibit aflatoxins synthesis by Aspergillus parasiticus: A biotreatment of three cereals for safe long-term storage. Biores Technol., 197:443-50. https://doi.org/10.1016/j.biortech.2015.08.113
Wang C, Esteve-Zarzoso B, Cocolin L, Mos A, Rantsiou K, 2015. Viable and culturable populations of Saccharomyces cerevisiae, Hanseniaspora uvarum and Starmerella bacillaris (synonym Candida zemplinina) during barbera must fermentation. Food Res Int., 78(12):195-200. https://doi.org/10.1016/j. foodres.2015.10.014

Windels CE, Kommedahl T, 1982. Pea cultivar effect on seed treatment with Penicillium oxalicum in the field. Phytopathology., 72(5):541-3. https://dpo.org/10.1094/Phyto-77-541 